\title{
The Role of Form-Focused Instruction on Foreign Language Learners
}

\author{
Mana Alahmad \\ Islamic Azad University, Central Tehran Faculty of Foreign Languages, Iran \\ mana.alahmad60@gmail.com
}

\begin{abstract}
To determine the role ofform-focused instruction on foreign language learners, this study demonstrates noticing necessary in foreign language learning. In other words, an instruction through input enhancement have an effect on foreign language learning. The participants in the study were 80 students who enrolled in Shamim Language Institute, but only 60 intermediate learners were selected by means of administering a placement test. Based on the results of the placement test, two matched groups, one as the experimental group and the other as the comparison group, were formed. So, the study utilized the experimental paradigm and tested the notion of focusing on form $(F o n F)$ as input enhancement for learning. The enhanced text, including conditional sentences as the treatment, time (pretest versus posttest), and task type (a multiple choice test and a cloze test) were used to conduct the study. The participants in control (FonM) group received the unenhanced text and discussed the topic in that session. And experimental group (FonF) concurrently received the same text enhanced and discussed it. To compare the means and the standard deviations of the pretest and the posttest tasks within the treatment, the researcher used T-Test. The results showed that type of instructional treatment led to differences in language learning in the short-term. The scores of the participants demonstrated that the experimental group outperformed the comparison group.
\end{abstract}

Keywords: Form-focus instruction; implicit learning; noticing;input enhancement

\section{Introduction}

Many researchers have attempted to define the forms of instruction which can be applied to the second/foreign language classroom and there are still some serious discussions over the exact and accurate terminology (Long, 1991; Doughty and Williams, 1998b; Ellis, 2001). The most widely used terms are those established by Long (1991). He makes the following distinctions: 1) Focus on FormS (FonFs), defined by teaching the forms rather than the meanings they convey (e.g., the grammar-translation method); 2) Focus on Meaning (FonM), explained by paying no attention to the forms while conveying a message, the instruction is to communicate only; and 3) Focus on Form (FonF), a balance between a Focus on FormS and a Focus on Meaning: "focus on form consists of an occasional shift of attention to linguistic code features by the teacher or one or more students" ( Basturkmen, Loewen, \& Ellis, 2002, p. 3). This shift occurs during communication.

Up to the present time, the bulk of the research into the effects of second language instruction have recorded the linguistic progress of one group exposed to an FonF approach and another exposed to FonFs instruction (Ellis, Basturkmen, \& Loewen, 2002; Loewen, 2003). The present study aims to further explore this area, concentrating on the effect that FonF, and FonM have on the acquisition of a grammatical form with communicative value: the six forms of conditional sentences have been selected.

Studies on the effectiveness of focus-on-form instruction have increased greatly and suddenly in recent years. Ellis et al (2002) improved Long's (1991) definition of FonF instruction by making the difference between two types: 'Planned focus-on-form' and 'incidental focus-on-form.' In many studies, focus on form was the result of prior planning on 
the part of the researcher/teacher. A large amount of this research (Leow, 2001; Fotos, 1994) has been listed under the term 'planned focus on form' (Ellis et al, 2002), involving 'intensive attention to Ellis's (2001) preselected forms'. In 'incidental focus on form' (Ellis, 2001), attention is distributed to a larger range of forms and none of these forms is already selected for instructional treatment (Loewen, 2003; Ellis, Basturkmen, \& Loewen, 2002). The effectiveness of focus on form is also based on the role of learners' attention in language learning, and input enhancement is indeed described as one technique of focus on form (Sheen, 2000; Leow, 2001, 2003).

The basic method of visual input enhancement involves increasing the perceptual salience of the target form by using a combination of different 'formatting techniques such as bolding, capitalizing and underlining of target forms. Input enhancement is considered to be an unobtrusive means of drawing the learners' noticing of linguistic forms, and is accordingly placed at the implicit end of the explicit-implicit continuum" (Sheen, 2000). It was hypothesized that this enhancement would take learners' attention to these emphasized forms, which should theoretically promote better noticing and further processing of the attended forms when compared to unenhanced input (Sharwood Smith, 1994).

There are many aspects of second language acquisition such as the strategy of learning, the role of communicative language teaching, the role of formal grammar teaching etc. This study has chosen the role of form-focused instruction in teaching grammar because of two reasons. First, teaching of grammar has generated a great discussion in second language teaching and a lot of research has been done on it. Second, there is an indication that grammar teaching has been neglected in English teaching in favor of developing communicative competence in language, which results in students having poor knowledge of grammar (Adnan, 1995). It is known that the second reason is not really common in Iran. It is to investigate formfocused instruction through textual enhancement. The target form is the conditional sentences and they are known to be difficult for many English second language learners because of the syntactic and semantic complexities (Larsen-Freeman, 2001). These learners have difficulty in their production (speech and writing).This form is part of the macrostructure of the text and contains the logical organization of the text which the writer has used to represent the intended meaning.

\subsection{Research question and hypothesis}

An issue of great concern to second language acquisition research and pedagogy over the past two decades has been whether the instruction should be explicit or implicit, whether the process of acquiring an L2 is a conscious or subconscious process, and whether consciousness is necessary at all in the process of internalization of information. Different positions have been identified: acquisition takes place subconsciously (Krashen's Acquisition Hypothesis), acquisition is largely a conscious process (Schmidt, 1994), and acquisition is partly conscious and partly subconscious (Tomlin \& Villa, 1994). There are many aspects of second language acquisition such as the stategy of learning, the role of communicative language teaching, the role of formal grammar teaching etc. This research is an attempt to answer the following question:

Is Form-focused instruction (or noticing) necessary or at least facilitative in foreign language learning? In other words, does such an instruction through input enhancement have an effect on foreign language learning? Taking this question into account the following hypothesis is proposed: 
Hypothesis1: Form-focused instruction plays a significant role in foreign language learning. Paying attention to language forms through input enhancement is facilitative and causes learners' accuracy in the experimental group to be increased. This Study has concentrated on the Input Hypothesis as part of an acquisition theory. It has shown how it reflects an ignorance of the nature and goals of linguistic theory and of language acquisition theory. Researchers had become aware of the need to examine input with which the learners had to work and recognized that all input would not become intake. With regard to the quantity of the input, many researchers supported the hypothesis that learners who have the opportunity to use the L2 will have the most proficiency. Research in the area of input quality led to the relation between certain characteristics of the input (perceptual saliency, frequency of occurrence, syntactic complexity, semantic complexity, instructional sequence) and some aspect of the learners' output (Larsen-Freeman, 1991, p.320).

\section{Review of Literature}

Hassani (1990) investigated the effect of deductive instruction on the improvement of English pronunciation in adult language learners. To test the hypothesis of this study (deductive instruction improves pronunciation), a laboratory experiment was done on two groups of adults who had no previous knowledge of English language. The experiment consisted of four English consonants $/ \theta /, / \circlearrowright /, / \mathrm{w} /$, and American $/ \mathrm{r} /$. These sounds were put in simple words; thus, sixteen words were assigned for the experiment. These words were read to the subjects on a tape. The subjects were asked to repeat the words after the speaker and their pronunciation were recorded. The subjects in control group were given no instruction. But the experimental group was given a deductive instruction about how to pronounce the sounds. The two groups' pronunciation was scored by three judges. Hassani concluded from his experiment that deductive instruction has an effect on learners' ability to produce specific linguistic features accurately.

Zargavafa's (1994) study was to find out whether grammatical consciousness-raising could facilitate English language acquisition for Iranian students. For such a purpose, English question formation was selected as the grammatical point to determine the effect of consciousness-raising on its acquisition. Three groups of students, who were studying English in an intensive course, were chosen and after four weeks of communicative instruction, they were pre-tested on English question formation. One as the experimental group was taught the form using grammatical consciousness-raising activities. And the other groups were taught communicatively for the four weeks. Then the three groups were post-tested. It was concluded that grammatical consciousness-raising activities (i.e. form-focused instruction) could facilitate learning of English question formation, or in general sense, English language acquisition.

Golkar's (1996) study aimed at investigating the impact of implicit logical connectives on English foreign language learners' reading comprehension and their interaction with proficiency level of students. A sample of 100 subjects from Mashad University, Allameh Tabatabai University, University for Teacher Education, and Tehran University were chosen. Based on their scores on the TOEFL test, they were assigned to two groups. The control group took version A of the reading texts with explicit connectives, the experimental one took version B with implicit connectives. Results revealed a statistically significant difference between the reading comprehension texts of the two groups, implying that implicit logical connectives lowered the learners' reading comprehension. But no significant interaction was observed between explicit/implicit logical connectives and proficiency level. 
English for special purposes (ESP) reading programs often take specific grammar, vocabulary, and isolated reading skills as the organizing principle for syllabus design and fail to acknowledge how the act of comprehending text can affect reading ability. Hashemi's (2000) study was conducted to examine the role of focus on form on ESP reading comprehension. The materials for the 2-year course were developed around thematic units which correspond to undergraduate course content. Instruction presented grammar and vocabulary only as they were necessary for comprehension of the text. The study examines whether the emphasis on reading for content improved reading comprehension as well as knowledge of reading grammar and general reading ability. Psychology students $(\mathrm{N}=50)$ were selected who administered three reading tests: reading grammar, comprehension, and cloze in experimental and control groups. Significant differences were found for instructional status and subtest and for each subtest by instructional level. The results of this study suggest that the content comprehension approach can improve reading comprehension as well as knowledge of reading grammar and general reading ability.

Another article in title of Study of Blended-Learning Method Assisted By Edmodo in Teaching English at State Vocational School in Deli Serdang by Rini Ekayati aims to describe blended-learning method assisted by Edmodo in teaching English at State Vocational School in Deli Serdang. Descriptive qualitative method was used in this study in order to examine factors, expected methods, and the pattern in teaching English at State Vocational School in Deli Serdang, by administrating questioner, interview, and observation as source of data taken from the sample.

A paper by Ramlan Ramlan in title of The Correlation between Language Acquisition and Language Planning demonstrates Language acquisition is a process which can take place at any period of one's life. In the sense of first language acquisition, however, it refers to the acquisition (unconscious learning) of one's native language (or languages in the case of bilinguals) during the first 6 or 7 years of one's life (roughly from birth to the time one starts school).Language acquisition planning has a significant correlation to the language acquisition by the students. Because the students' age in between zero up to five years is the appropriate moment to acquire a certain language.

\subsection{Subjects}

\section{Research Method}

The participants in the study were 80 students who enrolled in Shamim Language Institute. In this study gender and age were not variables; however, all of the participants were female and from the age of 15 up. To achieve an approximate homogeneity of subjects in terms of level, a placement test was administered to rank participants and divide them into two groups: One experimental group and one control group. This test was taken from The newest English tests written by Tajik (1376) and Five English test books written by Aflacki (1378). An English placement test complied by Oxford University Language Centre was concurrently given to this group. And correlation coefficient was used to determine the validity of the test. The obtained correlation coefficient was 0.81 . And to check the reliability of the test, KR-21 formula was developed. The estimated reliability of the test was 0.78 . The placement test, "Review your English knowledge", and its criterion measure (standard test) are displayed in Appendix 1.

Based on the information from the normal curve (mean and standard deviation), the subjects were divided into two groups in terms of their English knowledge. Those subjects 
whose scores were equal to or beyond 21 [mean (27) - /+ SD (6)] were placed in the experiment. In other words, the cut-off score for entering the research was 21-33. Those below 21 or above 33 were eliminated. This cut-off score was indeed based on the Oxford placement test scores. In other words, among the 80 participants, 12 students, who were very high, knew the rules and 8 students could not answer the test accurately. And the rest (two classes of intermediate English, $\mathrm{N}=60$ ), who obtained the cut-off score, formed a nearly homogeneous group. So, they were chosen in the study.

\subsection{Materials}

\section{A. Teaching materials (Target Forms)}

Since the FonF technique employed in the current study involved visual input enhancement which is considered to be one of the implicit ways of drawing the learners' attention to form, it was deemed important to choose a form that had some semantic value. This decision was motivated by previous research findings (White, 1998; Doughty \& Williams, 1998) on implicit FonF which have suggested that learners should notice forms with more semantic or communicative value in them. Upon consulting with English teachers, conditional sentences were chosen as the target linguistic forms.

Conditional sentences are among the most difficult structures for second language learners to master because the grammatical tense of the verb does not always match the meaning. Conditional sentences express a relationship in which one situation depends on another. Often introduced by if statements, they express three kinds of condition: real or possible conditions, hypothetical conditions, and impossible or unrealized conditions (Chou, 2000).

This study investigated six conditional types. Five of them were frequently emphasized in English second language or English foreign language instruction of conditionals, and they were included in various English second language or English foreign language grammar materials. These five conditional types were present factual, future predictive, present counterfactual, past counterfactual, and mixed-time-reference counterfactual conditional. The examples are quoted from various sources (No.1-4 from Celce-Murcia and Larsen-Freeman, 1999, pp. 549-551; No.5a from Yule, 1998, p. 126) (Chou, 2000, p.66-67).

Table 1. The Six English Conditional Types Assessed in the Study

\begin{tabular}{|l|l|l|}
\hline Conditional type & \multicolumn{1}{|c|}{$\begin{array}{c}\text { Grammatical } \\
\text { features } \\
\text { of verb in IF-C }\end{array}$} & $\begin{array}{c}\text { Grammatical } \\
\text { features of verb in } \\
\text { MC }\end{array}$ \\
\hline $\begin{array}{l}\text { 1. Present factual } \\
\text { If I wash the dishes, Sally dries them. }\end{array}$ & [-past $]$ & [-past] \\
\hline $\begin{array}{l}\text { 2. Future predictive (strong prediction) } \\
\text { If it rains, I will stay home. }\end{array}$ & [-past] \\
\hline $\begin{array}{l}\text { 3. Past factual } \\
\text { If Nancy said, "Jump!" Bob jumped. }\end{array}$ & [+ past] & [+ past $]$ \\
\hline $\begin{array}{l}\text { 4. Present counterfactual present } \\
\text { If I were the President, I would make } \\
\text { some changes. }\end{array}$ & [+ past] & [+ modal] [+ past] \\
\hline \begin{tabular}{l} 
5. Past counterfactual \\
\hline
\end{tabular} & & \\
\hline
\end{tabular}




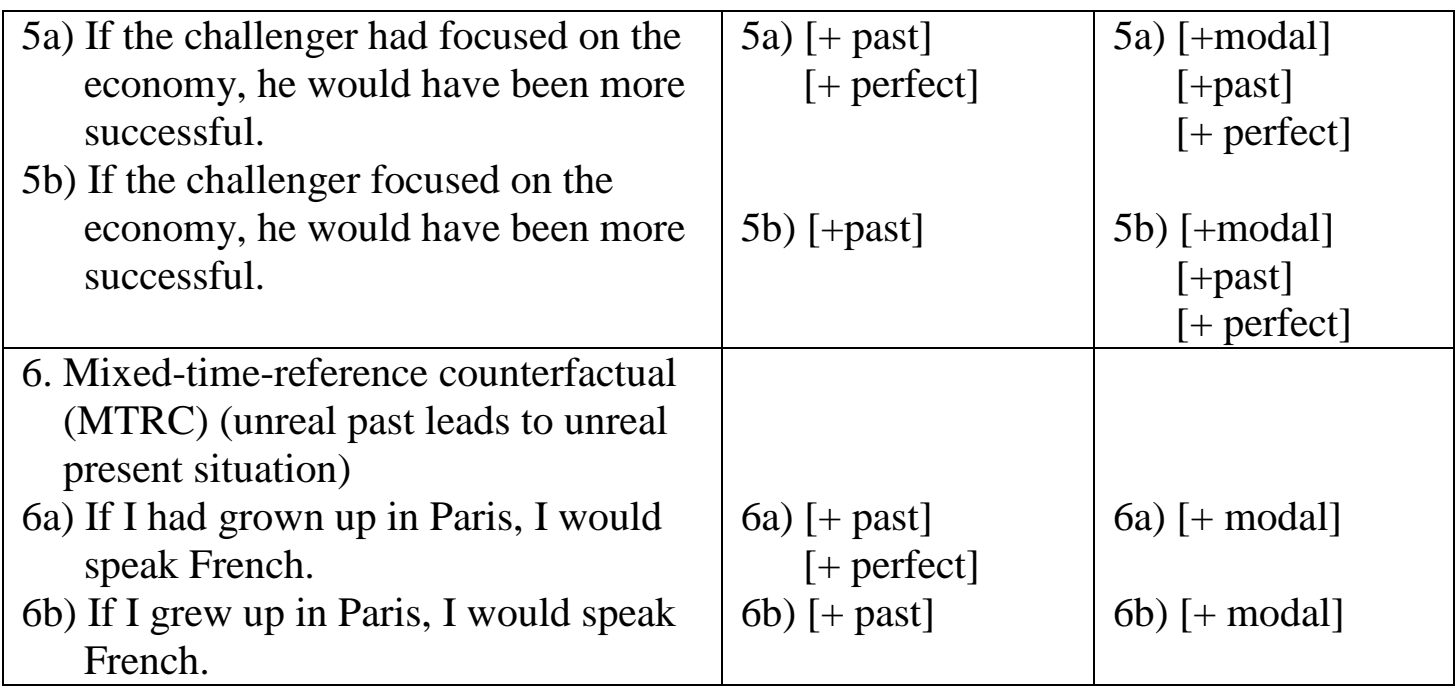

\section{B. Instrumentation}

The following materials were used to conduct this study: A multiple-choice test and a cloze test which constituted the pretest and post-test, and one instructional treatment. To obtain criterion-related validity and reliability of both multiple choice test and cloze test, the researcher used correlation coefficient and KR-21 formula. To determine validity and reliability of the tests, the researcher administered the tests to a knowledgeable group of forty five (senior high school) students in advance. Then, the researcher gave the tests and the treatment in the two classes of intermediate English and did not inform the participants at any time during the experiment. Below is a full account of the characteristics of each of them.

\section{1) Multiple- choice test}

The written test used as the pretest was a multiple-choice test. It included 30 items of conditional sentences and other grammatical structures so that the participants did not take much notice of what it is that the test was going to measure. Indeed, the pre-test was administered to sure completely about the measurement of the learners' developmental stage. The obtained scores of this achievement test indicated that subjects did not have much knowledge of conditional sentences. The test was taken from English sentence structure tests written by Aghajani \& Hejazi (1378). The multiple choice test and its standard test are displayed in Appendix 2.

\section{2) Treatment}

The researcher did not provide the participants with the feedback on the pretest. In order to instruct learners the targeted structure of the study, the researcher provided a fifty minute passage including the conditional sentences. This text, "On the Horn of Dilemma", was retrieved from World Wide Web: http:// www. English test.net.

In the control group, no attention was paid to the forms used to convey message, the instruction was devoted to communication only (in target language), on the theme of drafting. The focus was placed on the interpretation, expression, and negotiation of meaning. So, the participants concentrated on conveying a message and not on using conditional sentences accurately. The participants only read the passage and discussed the topic in the class. Implicit feedback (recasts with the appropriate correction but without explanation of the mistakes) was provided to them. In other words, after reading the text, learners talked about the topic itself and expressed their ideas. The researcher 
only asked some questions to help the discussion of the topic to be continued and it did not matter what has been in the text. For example, these questions were "what is your idea about drafting? Or is it necessary for women to join army?" If they used the wrong form, the correct form was only repeated without any explanation. See Appendix 3 for the reading passage given to control group.

In the experimental group, grammar instruction and communicative language use were integrated through input enhancement because "FonF is a balance between a FonFs and a FonM" (Long, 1991). In order to focus participants' attention on the forms, the researcher provided a sample of reading passage in which conditional sentences (six types) were highlighted by means of underlining, boldfacing, and changing of the font (Appendix 4). The subjects read the passage while focusing their attention on the target form and like control group discussed the topic. When learners read the text, some asked about the italic elements of the text. They were told that this boldfacing is not important and it is only the result of some types of error typing and word program, or the writer's taste that some parts have been more important because the text from the Internet is downloaded. To see whether they have focused on the italic and bold elements, the researcher asked some questions to force them to look at the text in order to answer them and become capable to continue the discussion. For example, they were" what did you do if you were him? What was his aunt's idea? What did the black sheep tell him?"

\section{3) Cloze test}

The reading passage of the post-test was a cloze test. It included 20 blanks with the main verbs in parentheses. This test format has been selected since conditional sentences are easily answered in multiple-choice tests and are difficult to be used in speech or writing. The test was taken from Chinese speakers' acquisition of English conditionals: Acquisition order and L1 transfer effects written by Chou (2000). The sample test and its standard test are displayed in Appendix 5.

\subsection{Design of the study}

In order to test the research hypothesis, the study utilized the experimental paradigm. The design of this study is referred to as the pretest-posttest-control group design. There were two groups: One experimental group and one control group. The experiment tested the notion of focusing on form (FonF) as input enhancement for learning. And the subjects were randomly selected and assigned to both groups. Using this design, the researcher could make sure that the experimental and control group were almost equal before the experiment since the result of the pretest in the two groups was nearly similar, but the result of the post-test of the groups was different. It becomes clear that the difference is because of the effect of the treatment.

\subsection{Procedures}

The enhanced text, including conditional sentences as the treatment, time (pretest versus posttest), and task type (a multiple choice test and a cloze test) were used to conduct the study. The written test as the multiple choice test was given to the participants in the two groups. The following day the pretest, the participants in the control (FonM) group received the unenhanced text and discussed the topic in that session. And experimental group (FonF) concurrently received the same text enhanced and discussed it. Then, the results on the tests were compared to see the effect of the treatment the participants received. 


\section{Test administration}

To administer the test, the study required three sessions. In first session, the participants were given 30 minutes to find the correct choice among the given alternatives. In the next session, the reading comprehension texts were given to each group in the classes as a class activity to learn new forms and to use them. Finally, the participants were given 30 minutes to fill in the blanks of the test with the verbs in the parentheses.

\section{Scoring}

The same scoring measures were used in the pretest and post-test. One point was awarded for the choice of each correct item in the multiple choice test as the pretest and the irrelevant items were ignored. And one point was awarded if the participants wrote the correct tense (verb) in each blank.

\section{Discussion}

In order to determine whether the form-focused instruction significantly affected the participants, the data was submitted to a series of descriptive statistics. In other words, descriptive statistics was used to estimate the mean, variance, and standard deviation of the scores. As it has been indicated in Tables all inferential statistics were performed using the Statistical Package for the Social Sciences (SPSS) 13.0, employing a probability level for rejection of $\mathrm{p}<.05$. To compare the means and the standard deviations of the pretest and the post-test tasks within the treatment, the researcher used T-test.

\subsection{Reliability and validity of the tests}

To obtain criterion-related validity and reliability of both multiple choice test and cloze test, the researcher used correlation coefficient and KR-21 formula. The tests and their standard tests were concurrently administered to a knowledgeable group of forty five students. The results appear in the Table 2 and Table 3:

Table 2. Reliability estimation of the tests

\begin{tabular}{|c|c|c|c|c|}
\hline Tests & Number of items & Mean & Variance & Reliability \\
\hline Multiple-Choice Test & 20 & 14.5 & 2.29 & 0.60 \\
\hline Cloze Test & 20 & 13 & 2.7 & .071 \\
\hline
\end{tabular}

Table 3. Validity of the tests

\begin{tabular}{|c|c|c|c|}
\hline Test & $\begin{array}{c}\text { Number of } \\
\text { Pairs of Items }\end{array}$ & $\begin{array}{c}\text { Number of } \\
\text { Pairs of Scores }\end{array}$ & $\begin{array}{c}\text { Correlation } \\
\text { Coeficient }\end{array}$ \\
\hline $\begin{array}{c}\text { Multiple-Choice Test } \\
\text { (Pre-test and Barons') }\end{array}$ & 20 & 45 & 0.80 \\
\hline $\begin{array}{c}\text { Cloze Test } \\
\text { (Post-test and ECPE) }\end{array}$ & 20 & 45 & 0.84 \\
\hline
\end{tabular}

\subsection{Research question and its hypothesis}

This research is an attempt to answer the following question:

1. Is form-focused instruction (or noticing) necessary or at least facilitative in foreign language learning? In other words, does such an instruction through input enhancement have an effect on foreign language learning?

Taking this question into account the following hypothesis is proposed: 
Hypothesis 1: Form-focused instruction plays a significant role in foreign language learning. Paying attention to language forms through input enhancement is facilitative and causes learners' accuracy in the experimental group to be increased.

The hypothesis in response to the research question predicted that Form-focused instruction would play a significant role. Descriptive statistics indicate that the experimental group (FonF) made more improvement than the control group. The means and the standard deviations of the scores from pretest to post-test are displayed in Table 4:

Table 4. The Mean Scores and Standard Deviation of the Tasks

\begin{tabular}{|c|c|c|c|}
\hline Test & Mean/N/SD & Control Group & Experimental Group \\
\hline \multirow{3}{*}{ Multiple-Choice Test } & Mean & 8.7 & 8.9 \\
\cline { 2 - 4 } & $\mathrm{N}$ & 30 & 30 \\
\cline { 2 - 4 } & $\mathrm{SD}$ & 2.12 & 1.95 \\
\hline \multirow{3}{*}{ Cloze Test } & Mean & 9 & 10 \\
\cline { 2 - 4 } & $\mathrm{N}$ & 30 & 30 \\
\cline { 2 - 4 } & $\mathrm{SD}$ & 1.9 & 1.5 \\
\hline
\end{tabular}

For the pretest that occurred prior to treatment, t-test formula was performed.

As shown in the Table 4.3, the means and standard deviations did not show a significant difference. T-test procedure showed that the observed $\mathbf{t}$ value was smaller than the critical $\mathbf{t}$ value. T-observe was $\mathbf{+ 0 . 4}$. It was compared to t-critical which was $\mathbf{2 . 0 0 0}$, according to the level of significance (.05) and df (58). So, the difference between the means is said not to be statistically significant.

But the means and standard deviation in FonF (experimental group) showed a significant difference from the FonM. The results suggest that the FonF instruction had an effect on the grammatical ability of the participants measured by the fill-in the blanks test. This finding is similar to other Focus-on-Form studies that have reported learners' ability to recognize and produce forms correctly would be increased when the researcher focuses learner's attention on a particular linguistic item while doing communicative activities (Fotos, 1994; Ellis, 2001). According to Schmidt's (1990) Noticing hypothesis, knowledge of specific linguistic items in the input is necessary for language learning to happen.

In other words, the hypothesis in response to the question supposed that paying attention to language forms through input enhancement would be facilitative and cause learners' accuracy in the experimental group to be increased. T-test formula was performed, the results of which showed a significant main effect on the post-test in the experimental group. A comparison of the mean scores also clearly indicated that the FonF group (Experimental group) performed better than the FonM participants (Control group). The results of the T-test procedure have been shown in Table 5:

Table 5. T-test for Instruction through Input Enhancement

\begin{tabular}{|l|c|c|c|c|c|}
\hline Categories & Mean & SD & t- Observed & t- Critical & d.f \\
\hline Control Group & 9 & 1.9 & 2.22 & 2.000 & \multirow{2}{*}{58} \\
\hline Experimental Group & 10 & 1.5 & & & \\
\hline
\end{tabular}
$\mathrm{P}<.05$

As shown in the Table 5, the observed $\mathbf{t}$ value is greater than the critical $\mathbf{t}$ value. So, the difference between the means is said to be statistically significant. In other words, the instructed 
treatment had a main effect on comprehension of conditional sentences measured by a cloze test at the intermediate (FonF and FonM) level. What do these respective instructions have in common that leads to an increase in comprehension among all instructed participants?

The object of the FonM approach is interpretation, expression, and negotiation of meaning. The researcher as the instructor of the FonM group provided the students with the topic that required them to use the conditional sentences in different forms to convey a message and negotiate meaning. And the students who were taught with a FonF approach, received grammar instruction and communicative language use through input enhancement task. In these methods, instruction promoted noticing of the target forms. While most second language acquisition researchers accept the value of promoting noticing, some even consider it as a necessary condition for language learning to occur (Schmidt, 1990).

\section{References}

Al-Hejin, B. (2004). Attention and awareness: Evidence from cognitive and second language acquisition research. Columbia University Working Papers in TESOL \& Applied Linguistics,4(1), pp.1-22. Available: http://www.colombia.edu.

Basturkmen, H., Loewen, S., \& Ellis, R. (2002). Metalanguage in focus on form in the communicative classroom. Applied Language Studies \& Linguistics, 11(1),1-13. Available: http:// www.auckland.edu/0965-8416/02/010001-12\$20.00/0

language, 9(3), 1-13. Available: http:// www.altaesl.com/dtail.cfm?catalog ID=11920\&

Brown, H. D. (2000). Principles of language learning and teaching. USA: Longman, Inc.

Combs, C. H. (2003). What cognitive processes are we triggered by input enhancement? TESOL \& Applied Linguistics, 4, Special Issue, 1-14. Available: http://www.colombia.edu/language

De Graaff, R. (2000). The Esperanto experiment: Effects of explicit instruction on SLA. Unpublished Research Report, University of Amsterdam. Available: http://www.amsterdam.edu/degraaff

Doughty, C. J. \& Long, M. H. (2001). Optimal psycholinguistic environments for distance foreign language learning. Second Language Studies, 20(1),

1-42. Available: http://www.hawai'i.edu/SLS/

Ekayati1 , Rimi. (2019). Study of Blended-Learning Method Assisted By Edmodo in Teaching English at State Vocational School in Deli Serdang. Linguistlist. Available:

www.bircu-journal.com/index.php/birle

Poole, A. (2006). The kind of forms learners attend to during focus on form instruction: A description of an advanced ESL writing class. Asian EFL Journal, 5(1). Available: http://www.journal.edu/articles/poole/article.pdf.

Ramlan Ramlan , 2018. The Correlation between Language Acquisition and Language Planning. Available at www.birci-journal.com

Schmidt, R. W. (1994). Deconstructing consciousness in search of useful definitions for applied linguistics. AILA Review, 11, 11-26.

Sheen, R. (2000). Review: Doughty \& Williams: Focus on form in SLA-part1. Linguist List 11.1598. Available: http://www.emich.edu/linguist/issues/ 1598.11/11-ntm

Siyyari, M. (2005). A comparative study of the effect of implicit and delayed, explicit focus on form on Iranian EFL learners' accuracy of oral production. Unpublished masters' thesis abstracts, University of Tehran. 